\section{Radiation Resistance of Gadolinium Zirconate Pyrochlore}

The pyrochlore structure-type is a proposed host phase for the immobilization of plutonium. Previous studies have shown that a wide variety of actinide pyrochlores can be synthesized. Gadolinium zirconate with the pyrochlore structure has been shown to be remarkably radiation resistant. We report additional results of ion-beam irradiation studies.

Samples of $\mathrm{Gd}_{2} \mathrm{Zr}_{2} \mathrm{O}_{7}$ and three variations from the ideal composition $\left(\mathrm{Gd}_{2} \mathrm{Zr}_{1.8} \mathrm{Mg}_{0.2} \mathrm{O}_{6.8}, \mathrm{Gd}_{1.9} \mathrm{Sr}_{0.1} \mathrm{Zr}_{1.9} \mathrm{Mg}_{0.1} \mathrm{O}_{6.85}\right.$, and $\left.\mathrm{Gd}_{1.9} \mathrm{Sr}_{0.1} \mathrm{Zr}_{1.8} \mathrm{Mg}_{0.2} \mathrm{O}_{6.75}\right)$ were prepared by solution combustion synthesis. All samples were confirmed to have the pyrochlore structure by electron diffraction. Irradiation experiments with $1.5 \mathrm{MeV} \mathrm{Xe} \mathrm{e}^{+}$and $1 \mathrm{MeV} \mathrm{Kr}^{+}$were performed using the HVEM-Tandem Facility at the Argonne National Laboratory.

All samples, irradiated to a dose of $8.9 \times 10^{15}$ ions $/ \mathrm{cm}^{2}$ (or $16 \mathrm{dpa}$, assuming

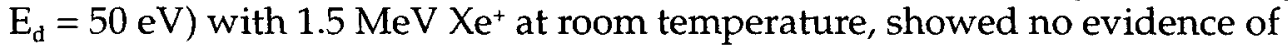
amorphization. A similar irradiation series with $1.5 \mathrm{MeV} \mathrm{Xe}^{+}$on the four samples was repeated at a temperature of $20 \mathrm{~K}$, and no amorphization was observed after a dose of $5 \mathrm{dpa}$. Clearly, compositions in this regime will be extremely stable and resistant to amorphization under repository conditions, even after reaching high radiation doses. All the samples experienced an irradiation-induced pyrochloreto-fluorite structural transformation, shown by HREM and SAED (Fig. 1).
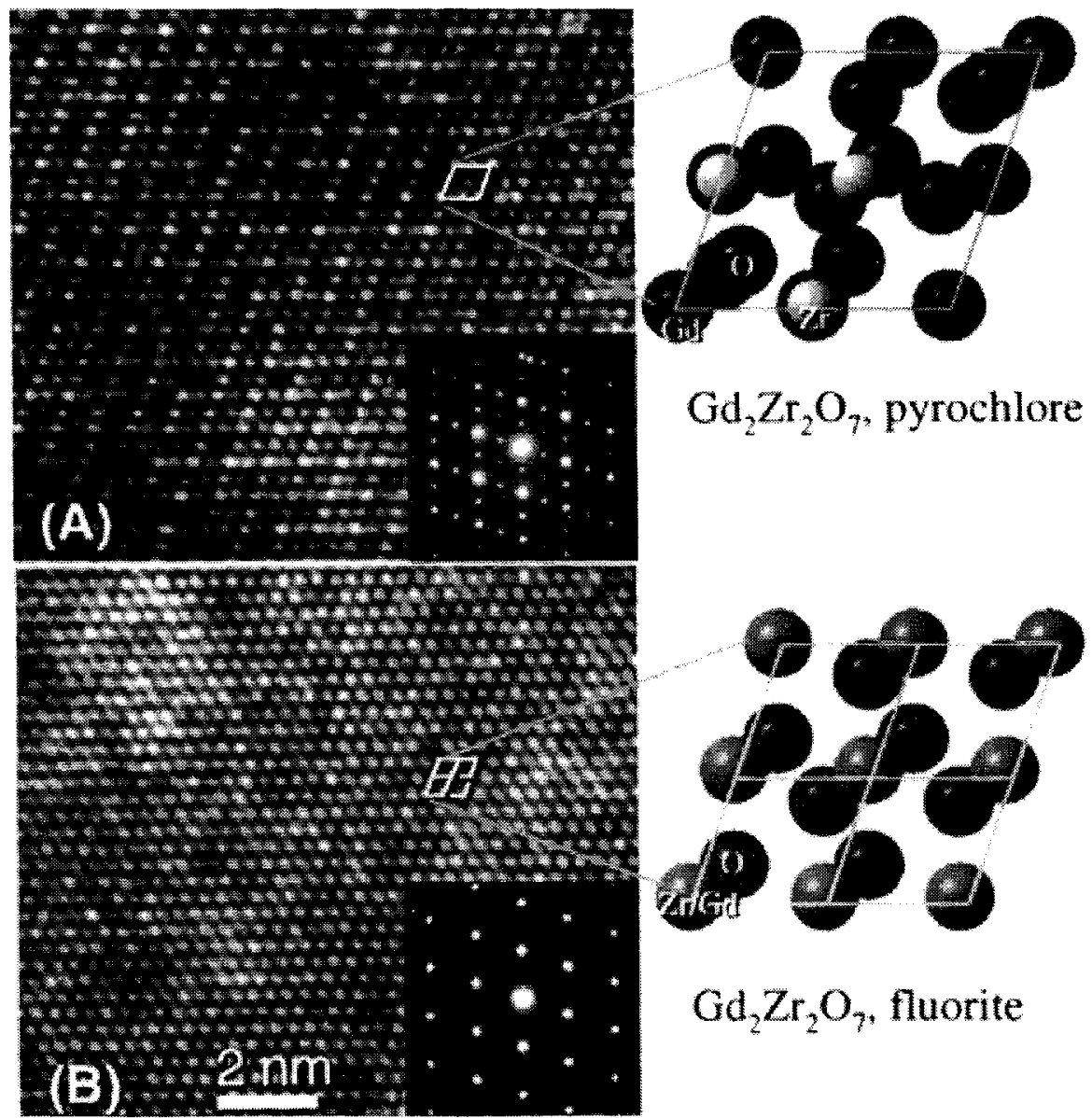

CP532, Plutonium Futures - The Science, edited by K. K. S. Pillay and K. C. Kim, (C) 2000 American Institute of Physics 1-56396-948-3/00/\$17.00
S.X. Wang, L. M. Wang, R. C. Ewing University of Michigan, Ann Arbor, MI 48109-2104, USA

K. V. Govidan Kutty Indira Gandhi Centre for Atomic Research, Kalpakkam 60312, India

W. J. Weber Pacific Northwest National Laboratory, Richland, WA 99352, USA

Figure 1. HREM image and electron diffraction patterns of $\mathrm{Gd}_{2} \mathrm{Zr}_{2} \mathrm{O}_{7}$ showing the transformation from pyrochlore (A) to fluorite (B) structure due to $1.0 \mathrm{MeV} \mathrm{Kr}^{+}$ irradiation. The order-disorder transformation is illustrated in the schematic crystal structures. 
Figure 2. Electron

diffraction patterns of ion-irradiated

$\mathrm{Gd}_{2} \mathrm{Zr}_{2} \mathrm{O}_{7}$ showing the diffuse maxima in addition to the basic diffraction patterns of fluorite structure. The indices are according to the fluorite structure.
Figure 3. (A) HREM image of irradiated $\mathrm{Gd}_{2} \mathrm{Zr}_{2} \mathrm{O}_{7}$. (B) Fourier transformation of the HREM reveals the diffuse patterns. (C) Inverse Fourier transformation of (B) using only the regular Bragg spots and the diffuse maxima. (D) The real diffraction of [110] zone showing the same diffuse patterns as in (B).

Diffuse maxima (Fig. 2) were observed in the electron diffraction patterns of all samples. The Fourier transformation (Fig. 3B) of the HREM image (Fig. 3A) showed similar diffuse patterns, as in the real electron diffraction patterns (Fig. 3D). Inverse Fourier transformation (Fig. 3C) of Fig. 3B using only the Bragg diffraction maxima and the diffuse maxima revealed nano-sized domains bordered by Moiré fringes, which are the source of the diffuse maxima in the diffraction patterns. The Moiré fringes can be attributed to overlap of nano-domains. Because of the strong tendency for simultaneous recovery, rather than amorphization, in the $\mathrm{Gd}_{2} \mathrm{Zr}_{2} \mathrm{O}_{7}$ and the heterogeneous nature of the damage by heavy ions, slightly rotated nano-domains with the fluorite structure form during irradiation.
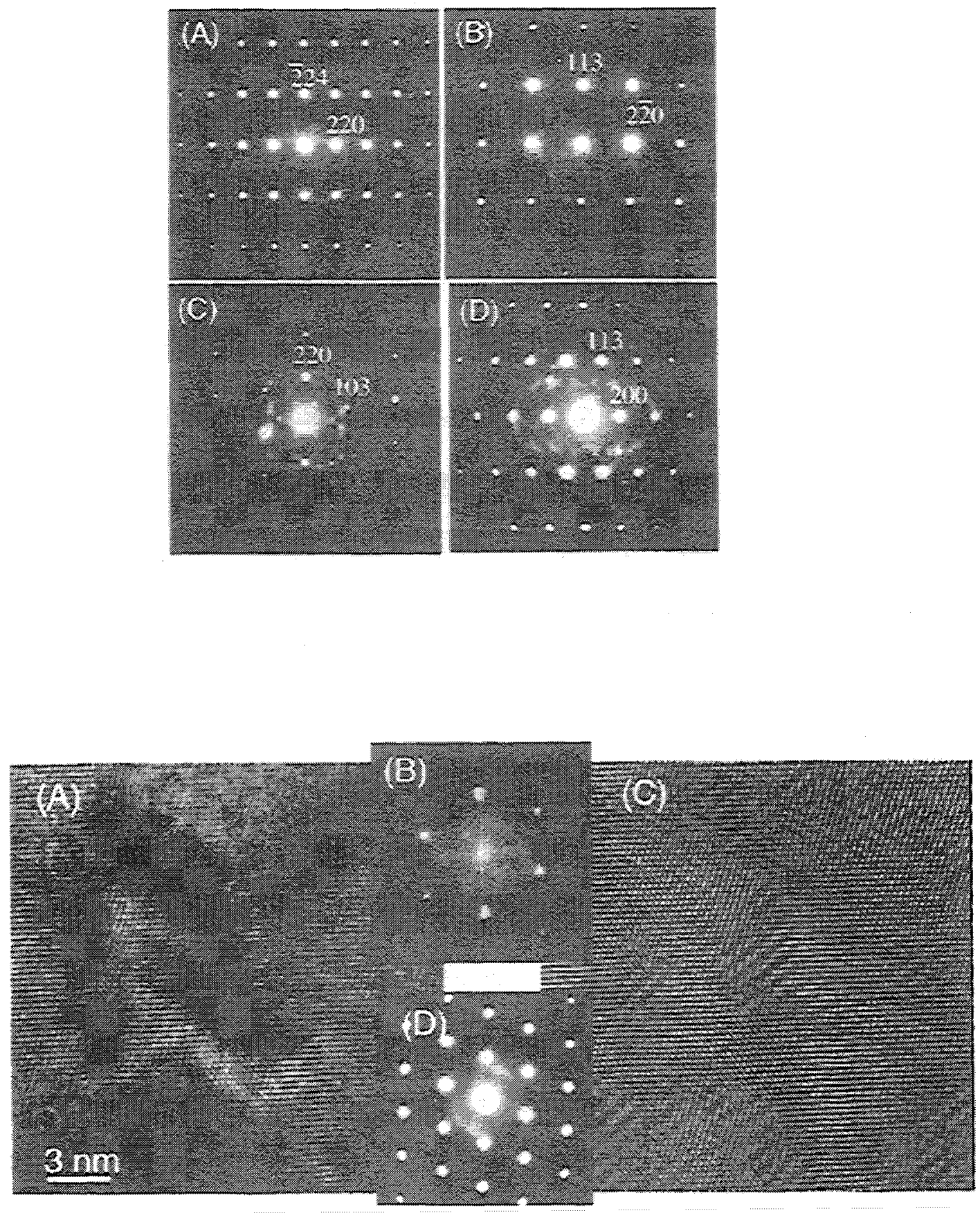
The pyrochlore-fluorite structure can incorporate a wide variety of different elements. Zirconate pyrochlore also has a superior chemical stability when in contact with water. The rare earths, particularly $\mathrm{Gd}$, in zirconates are effective neutron absorbers. The combination of all of these properties with its remarkable radiation resistance makes $\mathrm{Gd}_{2} \mathrm{Zr}_{2} \mathrm{O}_{7}$-based material an exceptionally promising host for the immobilization of plutonium.

\section{Acknowledgments}

This work was supported by the Office of Basic Energy Sciences, U.S. Department of Energy (DE-FG02-97ER45656). 